\title{
RÉGIMEN DE LAS RECLAMACIONES DE CONSUMO TRANSFRONTERIZAS EN EL NUEVO DERECHO EUROPEO DE RESOLUCIÓN ALTERNATIVA Y EN LÍNEA DE LITIGIOS DE CONSUMO *
}

\author{
Fernando Esteban DE LA Rosa
}

\begin{abstract}
SUMARIO: 1 . LA RESOLUCIÓN DE LITIGIOS EN LÍNEA: UN NUEVO ELEMENTO PARA LA PROTECCIÓN INTERNACIONAL DEL CONSUMIDOR.-2. EL NUEVO DERECHO EUROPEO DE RESOLUCIÓN ALTERNATIVA Y EN LÍNEA DE LITIGIOS DE CONSUMO.-2.1. Descripción general.-2.2. Funciones (y disfunciones) de la plataforma europea de resolución en línea de litigios.-2.3. Las entidades RAL acreditadas de los Estados miembros.-3. ÁMBITO DE APLICACIÓN DEL NUEVO DERECHO EUROPEO.-4. RÉGIMEN DE LA RESOLUCIÓN ALTERNATIVA DE LITIGIOS DE CONSUMO TRANSFRONTERIZOS.-4.1. Relaciones con las normas de competencia judicial internacional.-4.2. Cambios en la gestión de las reclamaciones transfronterizas derivados del nuevo marco institucional.-4.3. Cuestiones de Derecho aplicable.-4.3.1. Los modos de prestación del consentimiento para el inicio del procedimiento ante una entidad RAL.-4.3.2. Ley aplicable al sometimiento a entidades RAL: régimen general.-4.3.3. La determinación del Derecho aplicable a la enervación del carácter vinculante para el consumidor del pacto de arbitraje de consumo.-4.3.4. Régimen del consentimiento informado: cuestiones conflictuales y materiales.-4.3.5. El tratamiento de los pactos arbitrales de consumo por el Derecho europeo: relaciones entre el régimen del art. 10 DRAL y el de las cláusulas abusivas.-4.3.6. El nuevo valor del orden público en los pactos de sometimiento a tribunales arbitrales de consumo extranjeros.-4.3.7. La necesaria transposición del principio de libertad en todos los Estados miembros.-4.3.8. Ley aplicable al procedimiento ante las entidades RAL.-4.3.9. El respeto al Derecho imperativo aplicable al contrato de consumo.-5. CONCLUSIONES.
\end{abstract}

\footnotetext{
* Fellow of The National Center for Information Technology and Dispute Resolution (University of Massachusetts). Asociado del Instituto Hispano-Luso Americano de Derecho internacional. Este estudio ha sido realizado en el marco del Proyecto de Investigación I+D del Subprograma de Generación de Conocimiento, Programa Estatal de Fomento de la Investigación Científica y Técnica de Excelencia DER2014-56742-P, titulado «La adaptación de la legislación española al nuevo Derecho europeo para la resolución alternativa y en línea de litigios de consumo», del que es investigador principal el autor. El autor agradece la lectura del borrador y sugerencias de Pablo Cortés, Professor of Civil Justice, University of Leicester (Reino Unido). Fernando Esteban de la Rosa es Catedrático de Derecho internacional privado de la Universidad de Granada.Su correo electrónico es festeban@ugr.es.
} 


\section{LA RESOLUCIÓN DE LITIGIOS EN LÍNEA: UN NUEVO ELEMENTO PARA LA PROTECCIÓN INTERNACIONAL DEL CONSUMIDOR}

La revolución tecnológica ha supuesto una intensificación sin precedentes del comercio transfronterizo de consumo. Hoy cualquier consumidor puede celebrar contratos de compraventa o de servicios en línea, cuyo carácter transfronterizo en ocasiones resulta incluso de forma inopinada. Durante las últimas décadas del siglo xx el Derecho internacional privado europeo experimentó importantes avances en la regulación de los contratos de consumo. El Reglamento 593/2008, del Parlamento Europeo y del Consejo, de 17 de junio, sobre la ley aplicable a las obligaciones contractuales (en adelante Reglamento Roma I) y el Reglamento 1215/2012, del Parlamento Europeo y del Consejo, de 12 de diciembre, relativo a la competencia judicial, el reconocimiento y la ejecución de resoluciones judiciales en materia civil y mercantil (en adelante Reglamento Bruselas I bis) ${ }^{1}$ son solo el último exponente de la incorporación de elementos tuitivos en las normas de ley aplicable y en la acuñación de los foros de competencia internacional. Soluciones de ese corte gozan de buena salud en el Derecho comparado ${ }^{2}$ y recientemente han obtenido el respaldo, a nivel mundial, a través de la Resolución 1/2016 de la International Law Association ${ }^{3}$. Es sabido que el interés del legislador europeo por la protección del consumidor y la integración de los mercados ha motivado avances en la armonización del Derecho de protección del consumidor y en la generación de vías procesales dispuestas para conseguir una mejor efectividad de los derechos reconocidos a los consumidores, especialmente en los litigios de escasa cuantía.

Estos avances no logran ocultar el desfase entre el formalismo inherente a la presentación de una reclamación judicial y la realidad de un comercio electrónico de consumo caracterizado por su carácter masivo y por la escasa cuantía de las reclamaciones que genera, que demandan soluciones flexibles y ágiles a fin de dar satisfacción a las partes en un plazo breve y acompasado con la inmediatez que caracteriza a las relaciones a través de la Tecnología de la Información y de la Comunicación (en adelante TIC). Por ello, respecto del comercio en línea transfronterizo, el dispositivo de protección del consumidor de la Unión Europea, aunque necesario, se revela como insuficiente.

\footnotetext{
1 Véase la sección 4. a del capítulo II del Reglamento 44/2000, del Consejo, de 22 de diciembre, relativo a la competencia judicial, el reconocimiento y la ejecución de resoluciones judiciales en materia civil y mercantil (Bruselas I), DO L núm. 12, de 16 de enero de 2001; la sección 4. a del capítulo II del Reglamento 1215/2012, del Parlamento Europeo y del Consejo, de 12 de diciembre, relativo a la competencia judicial, el reconocimiento y la ejecución de resoluciones judiciales en materia civil y mercantil (Bruselas I), DO L núm. 351, de 20 de diciembre de 2012; así como el art. 6 y relacionados del Reglamento (CE) 593/2008, del Parlamento Europeo y del Consejo, de 17 de junio, sobre la ley aplicable a las obligaciones contractuales (Roma I), DO L núm. 177, de 4 de julio de 2008.

2 Véanse distintas referencias en el trabajo de RüHL, G., «La protección de los consumidores en el Derecho internacional privado», Anuario Español de Derecho internacional privado, 2010, pp. 91-120.

3 La Resolución del ILA puede ser consultada en la siguiente página web: http://tinyurl.com/grb$y 65 p$ (consultada el 3 de diciembre de 2016).
} 
En el siglo XXI el desarrollo de la TIC ha supuesto la incorporación de nuevos debates a la estrategia de protección del consumidor, especialmente en el ámbito del comercio digital. En primer lugar se ha pretendido favorecer el desarrollo del comercio en línea estableciendo para él un Derecho propio, si bien opcional. Sin embargo, tras detectarse variadas dificultades para su implantación, la propuesta de Normativa Común de Compraventa Europea fue finalmente abandonada ${ }^{4}$. En segundo lugar, el desarrollo de la TIC ha permitido la creación de sistemas que hacen posible la resolución en línea de litigios (online dispute resolución u $O D R$ por sus siglas en inglés). Las TIC son utilizadas no solo como una herramienta de comunicación, sino también a través de la denominada "cuarta parte» ${ }^{5}$. En efecto, las funcionalidades ofrecidas por las TIC son múltiples y variadas. Las TIC permiten la solución de litigios a través de la negociación directa, la negociación asistida (Assisted Negotiation), la negociación automatizada (Automated Negotiation), los sistemas de subasta ciega (blind-bidding), o la mediación y el peritaje de un tercero ${ }^{6}$. El potencial de la tecnología para dar respuesta a las necesidades de un comercio en línea en crecimiento constante explica la aparición de plataformas informáticas dispuestas a ofrecer esos servicios. Algunos mercados en línea, como eBay o Amazon, cuentan con su propio sistema de resolución de reclamaciones. Pero también hay plataformas independientes del empresario, públicas, como ECODIR, que fue promovida hace años por la Unión Europea $^{7}$, y privadas, entre las que cabe mencionar YOUSTICE ${ }^{8}$, eJustic ${ }^{9}$, Smartsettle ${ }^{10}$, MODRIA ${ }^{11}$ o Juripax ${ }^{12}$. La incorporación de estos servicios de resolución en línea ha ido más allá del ámbito de la resolución alternativa de litigios, y ya existen ejemplos de tribunales judiciales virtuales ${ }^{13}$, así como proyectos para su puesta en marcha a corto plazo ${ }^{14}$.

\footnotetext{
${ }^{4}$ En su lugar la Comisión Europea ha lanzado sendas propuestas de directivas relativas, respectivamente, a determinados aspectos de los contratos de suministro de contenidos digitales [Documento COM (2015) 634 final, de 9 de diciembre de 2015], y a determinados aspectos de los contratos de compraventa en línea y otras ventas a distancia de bienes [Documento COM (2015) 635 final, de 9 de diciembre de 2015].

5 Véase Katsh, E. y RIFKIn, J., Online Dispute Resolution: Resolving Conflicts in Cyberspace, San Francisco, Jossey-Bass, 2001, pp. 93-117; ScHULTZ, T., "An Essay on the Role of Government for ODR. Theoretical Considerations about the Future of ODR», ADR Online Monthly UMASS, 2003, p. 6.

6 Sobre la caracterización de estas diferentes funcionalidades, véase EsTEBAN DE LA Rosa, F., «Principios de protección del consumidor para una iniciativa europea en el ámbito de la resolución electrónica de diferencias (ODR) de consumo transfronterizas», Revista General de Derecho Europeo, vol. 25, 2011, pp. 7-9.

7 http://www.ecodir.org/ (consultada el 3 de diciembre de 2016).

8 http://www.youstice.com/ (consultada el 3 de diciembre de 2016).

9 http://www.ejustic.com/ (consultada el 3 de diciembre de 2016).

10 http://www.smartsettle.com/ (consultada el 3 de diciembre de 2016).

11 http://www.modria.com/ (consultada el 3 de diciembre de 2016).

12 http://www.juripax.com/modria.html (consultada el 3 de diciembre de 2016).

13 Sirva de ejemplo el tribunal virtual existente en la British Columbia canadiense, disponible en la web https://justice.gov.bc.ca/cso/index.do (consultada el 3 de diciembre de 2016).

14 En Reino Unido se ha anunciado la creación de un tribunal de resolución de litigios en línea para conocer de reclamaciones de hasta 25.000 libras. Véase CORTÉs, P., «The Digitalization of the Judicial System: Online Tribunals and Courts», Computer and Telecommunications Law Review, vol. 22(6), 2016, pp. 141-143.
} 
Desde diversos organismos internacionales se advirtió muy pronto el interés por disponer de un marco normativo para la resolución en línea de litigios, con miras a excluir que quedara exclusivamente en manos de los proveedores del servicio y de la autorregulación. Entre los primeros intentos cabe mencionar el incorporado a la agenda de la Organización de Estados Americanos ${ }^{15}$, de cuyos trabajos no ha habido ulterior noticia. A nivel universal, el Grupo de Trabajo III de la CNUDMI comenzó su andadura en 2010 con la intención de aprobar un marco legal para la resolución por vía informática de litigios derivados de transacciones electrónicas. La regulación vendría compuesta por cuatro instrumentos, a saber: un reglamento de procedimiento, unas directrices aplicables a los proveedores del servicio y a los terceros, unas reglas sustantivas aplicables a la solución de los litigios, adaptadas a la escasa cuantía y al pretendido carácter más simple de las reclamaciones y, por último, unas normas destinadas a facilitar la ejecución transfronteriza ${ }^{16}$. Los trabajos de la CNUDMI han finalizado en febrero-marzo de 2016 con un resultado menos exitoso del esperado. El consenso alcanzado se refiere a la aprobación de unas notas técnicas sobre la solución de controversias en línea que expresamente descartan su carácter de soft law ${ }^{17}$.

En el ámbito europeo, el 18 de junio de 2013 fueron adoptados el Reglamento 524/2013, del Parlamento Europeo y del Consejo, de 21 de mayo, sobre resolución de litigios en línea en materia de consumo (en adelante RRLL) y la Directiva 2013/11/UE, del Parlamento Europeo y del Consejo, de 21 de mayo, sobre resolución alternativa de litigios en materia de consumo (en adelante DRAL $)^{18}$. La nueva normativa europea pretende dar respuesta a la necesidad de desarrollo del mercado interior del comercio en línea. Se ha dicho que el art. 114 del Tratado de Funcionamiento de la Unión Europea (en adelante TFUE) no es la base más adecuada para esta legislación ${ }^{19}$. Sin embargo, tampoco sorprende, pues el fundamento de la construcción del mercado interior ha sido utilizado para promover la armonización de la protección del

15 Véase Del Duca, L., Rule, C. y Rogers, V., «Designing a Global Consumer Online Dispute Resolution (ODR) System for Cross-Border Small Value - High Volume Claims - OAS Developments», Stanford Public Law Working Paper No. 1635463, 6 de julio de 2010. El documento se encuentra disponible en la siguiente página web: http://ssrn.com/abstract=1635463 (consultada el 3 de diciembre de 2016).

16 Para una aproximación crítica a la iniciativa legislativa de la CNUDMI, véase CoRTÉs, P. y EsTEBAN DE LA Rosa, F., «Building a Global Redress System for Low-Value Cross-Border Disputes», International and Comparative Law Quarterly, vol. 62-2, 2013, pp. 407-440.

17 El último documento publicado, correspondiente al 33. ${ }^{\circ}$ periodo de sesiones, celebrado en Nueva York, del 29 de febrero al 4 de marzo de 2016, está disponible en la siguiente web: http://tinyurl.com/ j2jthdo (consultada el 3 de diciembre de 2016).

18 DO L núm. 165/1, de 18 de junio de 2013. Para un análisis sobre los elementos principales de la nueva normativa europea, véase EsteBAn DE LA RoSA, F. y CoRTÉs, P., «Un nuevo Derecho europeo para la resolución alternativa y en línea de litigios de consumo», en EsTEBAN DE LA Rosa, F. (ed.), $L a$ Protección del Consumidor en Dos Espacios de Integración - Una Perspectiva de Derecho Internacional, Europeo y Comparado, Valencia, Tirant lo Blanch, 2015, pp. 514-563.

19 Véase EidenmülLeR, H. y ENGEL, M., «Die Schlichtungsfalle: Verbraucherrechtsdurchsetzung nach der ADR-Richtlinie und der ODR-Verordnung der EU», Zeitschrift für Wirtschaftsrecht - ZIP, vol. 36, 2013, p. 1706, así como la STJ de 17 de marzo de 1993, asunto C-155/91, ECLI:EU:C:1993:98. 
consumidor a través de directivas, cuyo alcance no ha quedado limitado a la regulación de situaciones intracomunitarias.

Este estudio tiene por objeto revisar el impacto del nuevo Derecho europeo sobre las soluciones de Derecho internacional privado para la resolución alternativa de litigios de consumo transfronterizos y, especialmente, el modo en que aquellas se ven afectadas como consecuencia de la puesta en marcha de la nueva plataforma europea. Nuestra atención se centrará en los sectores de la competencia internacional y del Derecho aplicable. Para los fines del estudio no es posible ignorar la variedad de métodos de solución que emplean las entidades de resolución alternativa de litigios (en adelante entidades RAL) de los Estados miembros. La nueva regulación europea apenas cuenta con un número limitado de disposiciones especiales para los supuestos transfronterizos. Más allá, no se contempla ni la posible existencia de conexiones entre la resolución alternativa y el objetivo de los foros de competencia internacional, especialmente los especiales para la materia de los contratos celebrados por los consumidores, ni tampoco se contiene un régimen completo para las variadas cuestiones de ley aplicable que el nuevo Derecho ha hecho aflorar. Por ello, resulta necesario hacer una construcción del sistema que, además de arrojar luz sobre el acoplamiento en concreto entre las soluciones especiales y las generales, permita una aproximación crítica. Para esta labor cabe adelantar el importante papel hermenéutico que corresponde a la proclamación del derecho a la tutela judicial efectiva que hacen el art. 47 de la Carta Europea de los Derechos Fundamentales (en adelante CEDF) y el art. 19 del Tratado de la Unión Europea (en adelante TUE) a la hora de resolver diferentes cuestiones prácticas. Bajo esta orientación será posible valorar, por ejemplo, el acomodo que el nuevo sistema hace del arbitraje de consumo transfronterizo, que como veremos obliga a entender como superada la interpretación más frecuente hasta ahora del sistema general. O la respuesta que reciben en la regulación actual los problemas idiomáticos asociados al uso y gestión, respectivamente, de la plataforma europea y las plataformas nacionales de resolución alternativa de litigios de consumo. A la vista de esta aproximación crítica, el presente estudio incluye propuestas de lege ferenda con miras a conseguir respuestas más satisfactorias a las necesidades jurídicas de la gestión en línea de reclamaciones transfronterizas de consumo. Antes de pasar a la exposición del régimen de Derecho internacional privado (4), primeramente nos ocuparemos de describir los elementos principales de la nueva regulación europea (2), así como su ámbito de aplicación y las consecuencias que conlleva (3).

Una breve digresión antes de empezar sobre el impacto del reconocimiento de la libertad de establecimiento y de prestación de servicios en el ámbito de los servicios de resolución en línea de litigios. La posibilidad de que una entidad RAL acreditada en un Estado miembro pueda resolver litigios que involucren a consumidores con residencia en un Estado miembro distinto es algo que queda sobreentendido en la DRAL y en el RRLL. En este punto el nuevo Derecho europeo no ha introducido innovación respecto del 
sistema de colaboración que fue instaurado por la Red de Centros Europeos del Consumidor para la resolución de litigios transfronterizos y que daba a las entidades RAL del país del establecimiento del empresario la oportunidad de conocer de las reclamaciones presentadas por consumidores con residencia en otros Estados miembros. El art. 5.3 DRAL deja abierta la posibilidad de que una entidad RAL pueda estar establecida en un país que no coincida ni con el de la residencia del consumidor ni tampoco con el del establecimiento de la empresa reclamada. De ello debe poderse deducir que en este ámbito es reconocida la libre prestación de servicios sin establecimiento.

La DRAL, a su vez, crea una correlación entre el país de establecimiento de la entidad de resolución alternativa (art. 4.3 DRAL) y el país de acceso a la acreditación europea (art. 19 DRAL) de tal manera que cada entidad RAL que pretenda acceder a la acreditación deberá hacerlo en el país de su establecimiento. Esta posición viene refrendada por la legislación de algunos Estados miembros que han transpuesto la DRAL ${ }^{20}$. Sin embargo, el hecho de que otros Estados estén evitando esta especificación ${ }^{21}$, plantea la duda de si, a la vista de la jurisprudencia del TJ, será posible que una entidad RAL obtenga su acreditación en un país distinto al de su establecimiento, aprovechando unas condiciones de acceso a esta clase de actividad eventualmente más benévolas. Ello podría suponer la apertura de un mercado, a la baja (race to the bottom), para las acreditaciones de entidades RAL.

El reconocimiento de las libertades hace necesario valorar la compatibilidad con el Derecho europeo de las eventuales restricciones estatales que puedan establecerse a la acreditación. A falta de criterio europeo, entre los motivos que podrá tener en cuenta el TJ para considerar como compatibles con el Derecho de la Unión Europea tales restricciones cabrá invocar, por ejemplo, la necesidad de atribuir a una entidad RAL pública el monopolio de la resolución de litigios en un sector, con miras a evitar la confusión del consumidor, o la posibilidad de generar economías de escala en el funcionamiento de una entidad RAL, a fin de hacerlas más efectivas y permitir un mejor control y estudio de los problemas que surgen en un concreto sector económico. En este orden de cuestiones podrá ser necesario, por ejemplo, analizar si resulta en contradicción con las libertades mencionadas una normativa estatal que obligue a las empresas a quedar adheridas a entidades RAL acreditadas en su país, limitando la posibilidad de que puedan cumplir con esta obligación de adhesión a través de entidades acreditadas en otros

\footnotetext{
20 Para el Reino Unido, véase la sección 9.4 de The Alternative Dispute Resolution for Consumer Disputes (Competent Authorities and Information) Regulations 2015 (Reglamento 542 de marzo de 2015); Para el Derecho holandés véase el art. 1 letra $h$ ) de la ley holandesa Wetsvoorstel implementatie richtlijn RAL consumentengeschillen de 16 de abril del 2015; para el Derecho irlandés véase el art. 7.1, parte tercera de la European Union (Alternative Dispute Resolution for Consumer disputes) Regulations 2015.

21 Por ejemplo, el requisito no aparece en el art. 17 del Anteproyecto de Ley español de resolución alternativa de litigios de consumo, de 17 de abril de 2015, disponible en http://tinyurl.com/jx794jy (consultada el 3 de diciembre de 2016).
} 
países europeos. Este aspecto será especialmente relevante en los sectores económicos que ofrecen servicios a nivel transfronterizo, como es el caso de las aerolíneas de transporte aéreo que operan en varios países europeos. Al no aclarar demasiado la DRAL sobre estos puntos, cabe augurar interesantes decisiones del TJ con este objeto.

\section{EL NUEVO DERECHO EUROPEO DE RESOLUCIÓN ALTERNATIVA Y EN LÍNEA DE LITIGIOS DE CONSUMO}

\subsection{Descripción general}

Las obligaciones del nuevo sistema recaen sobre la Comisión Europea, sobre los Estados y sobre los empresarios. El conjunto normativo pivota sobre la creación de la plataforma europea de resolución alternativa y en línea de litigios de consumo, por una parte, y la necesidad de que los Estados cuenten con entidades RAL adaptadas al Derecho europeo. Las exigencias guardan relación con la cobertura por parte de entidades RAL de ciertos litigios, con el cumplimiento por estas entidades de unos estándares mínimos en su configuración y procedimiento seguido, y con la garantía de su conocimiento, para lo cual se contemplan obligaciones de información que recaen sobre los empresarios. Cada Estado, a través de sus autoridades competentes, ha de ocuparse de evaluar las solicitudes de acreditación de las entidades RAL y realizar sobre ellas una labor de supervisión sobre el cumplimiento de las condiciones establecidas. Los Estados han de adaptar el régimen de la caducidad y prescripción a fin de que el ejercicio de acciones judiciales no quede impedido por el transcurso del tiempo. El Derecho europeo quiere orientar la legislación estatal a fin de que se promueva, lo más posible, el conocimiento por los consumidores de la lista de entidades de resolución alternativa de litigios que cuenten con la marca europea (art. 15 DRAL), la cooperación e intercambio de experiencias entre entidades de resolución alternativa (art. 16 DRAL), así como la cooperación entre entidades de resolución alternativa y autoridades nacionales encargadas de la aplicación de las normas europeas de protección de los consumidores (art. 17 DRAL).

El RRLL entró en vigor el 8 de julio de 2013 y la puesta en marcha de la plataforma europea tuvo lugar el 15 de febrero de $2016^{22}$. Desde esta fecha los empresarios, también los establecidos en España, han de ofrecer en sus sitios de Internet un enlace electrónico a la plataforma de resolución de litigios en línea. Aunque el plazo para la transposición finalizó el 9 de julio de 2015, a día de hoy esta tarea está pendiente en tres Estados, entre ellos España. Como consecuencia no existen todavía entidades RAL españolas en la lista de la Comisión Europea. De las 17.500 quejas presentadas hasta el 26 de octubre, 1.500 lo fueron contra empresas españolas, de las cuales unas 1.000

${ }^{22}$ La plataforma está disponible en la siguiente página web: https://webgate.ec.europa.eu/odr/main/ index.cfm? event=main.home.show\&lng=ES (consultada el 3 de diciembre de 2016). 
correspondían a consumidores con residencia en España ${ }^{23}$. Pese a la falta de transposición, ha trascendido que la función de asistir a los consumidores en el caso de las reclamaciones derivadas de contratos transfronterizos ha sido encomendada al Centro Europeo del Consumidor en España.

\subsection{Funciones (y disfunciones) de la plataforma europea de resolución en línea de litigios}

La plataforma europea de resolución de litigios en línea es gestionada directamente por la Comisión Europea. Para ello el RRLL contiene unas normas de procedimiento uniformes que regulan, entre otras cuestiones, la presentación de la reclamación, la comunicación a la parte reclamada, el acuerdo sobre la entidad RAL que conocerá del caso o las causas de cierre y archivo de la reclamación (arts. 8 y 9 RRLL). Las normas de procedimiento resultan parcas en la regulación de ciertas cuestiones. Por ejemplo, aunque se da por sobreentendido que las partes han de ponerse de acuerdo sobre la entidad RAL que habrá de conocer del litigio, no se contiene una regulación sobre el modo en que deberá habilitarse la prestación del consentimiento y, ante todo, sobre el grado de información que ha de facilitarse al consumidor en ese momento. Este acuerdo, una vez que haya tenido lugar, no precisará que sea reproducido ante la entidad RAL receptora del caso que, por ejemplo, lleve a cabo el procedimiento en línea.

La plataforma europea no incorpora herramientas de negociación en línea, como la negociación asistida o la negociación automatizada. Opera básicamente como una ventanilla única para los consumidores y comerciantes que deseen presentar una reclamación. Para este fin los interesados pueden cumplimentar su reclamación de manera electrónica, de forma gratuita y en todas las lenguas oficiales de la UE. Conviene advertir que, aunque la cumplimentación de la reclamación es gratuita, se permite que las entidades RAL puedan cobrar por el servicio ofrecido. La plataforma europea cuenta también con una herramienta de tramitación en línea. Con ella se permite la comunicación de las partes con la entidad RAL competente, al igual que se hace posible la aportación de documentación. Como toda la plataforma, esta herramienta no solo está disponible para las reclamaciones transfronterizas sino también para las domésticas, que representan hoy el 60 por 100 de las presentadas. La página web contiene también la información sobre las entidades RAL acreditadas por los Estados miembros ${ }^{24}$ incluidas en la plataforma y en ella estarán disponibles los comentarios de las partes, con opiniones sobre su funcionamiento y sobre la entidad RAL que haya conocido del litigio.

\footnotetext{
${ }^{23}$ Información facilitada por personal de la Comisión Europea en la Jornada sobre el acceso del consumidor a los sistemas de resolución alternativa de conflictos organizada por la AECOSAN el día 26 de octubre de 2016.

${ }^{24}$ El 26 de octubre de 2016 había listadas 237 entidades RAL pertenecientes a 23 Estados miembros.
} 
El idioma del procedimiento ante una entidad RAL representa una cuestión clave para los casos transfronterizos, por lo que el régimen a que quede sometido debe ser objeto de un análisis especial. El régimen europeo muestra aquí luces y sombras. Por una parte, la reclamación puede ser presentada en todas las lenguas oficiales de la Unión Europea y, asimismo, se contempla una función de traducción electrónica automatizada, que cuenta con el apoyo logístico de los puntos de contacto nacionales. El objetivo es ayudar a las partes y a las entidades de RAL a intercambiar información. No obstante, la posibilidad de cumplimentar el formulario en cualquier idioma de la Unión Europea no significa que la entidad RAL seleccionada haya de tramitar la reclamación en ese idioma. En la operativa establecida, una vez que la queja es enviada a una entidad de RAL, la plataforma se ocupa simplemente de informar al consumidor acerca de la lengua en la que se llevará a cabo el procedimiento, a pesar de que los consumidores hayan podido tener la impresión de que podrán utilizar su idioma durante toda la tramitación.

La regulación actual de la plataforma europea genera una disfunción adicional. En la actualidad, en el 55 por 100 de los casos, si el empresario simplemente no responde a la invitación a participar en un procedimiento ante una entidad RAL, el asunto es archivado, sin que importe que aquel esté sometido por ley o por adhesión voluntaria a participar en el procedimiento. El hecho de que la plataforma, en estos casos, se limite a comunicar al consumidor el archivo del caso entraña el riesgo de generar en el consumidor la idea de que ha perdido la oportunidad de reclamar. Esta cuestión debería ser objeto de atención en una próxima revisión del RRLL a fin de facilitar al consumidor información de su interés sobre vías ulteriores de reclamación. En esta revisión cabría tener en cuenta las soluciones que ofrece en la actualidad el Protocolo para el tratamiento de reclamaciones de la Red de Centros Europeos del Consumidor (Protocol on case handling for the European Consumer Centers Network).

\subsection{Las entidades RAL acreditadas de los Estados miembros}

La resolución de los conflictos de consumo corresponde a las entidades RAL acreditadas en cada Estado miembro. Los Estados asumen la obligación de hacer disponibles entidades RAL suficientes para ofrecer una cobertura completa de los litigios incluidos en el ámbito de aplicación de ambos instrumentos. Las entidades RAL acreditadas han de disponer de una página web con información sobre sus procedimientos que, entre otras cosas, ha de permitir la presentación en línea de reclamaciones. A su vez, tienen que cumplir con unos estándares de calidad que se cifran en la exigencia de unos conocimientos especializados mínimos al personal que se ocupa de gestionar la reclamación, y en los provenientes de los principios de independencia e imparcialidad, de transparencia, de eficacia, de equidad, de libertad y de legalidad ${ }^{25}$.

25 Véase Cuenca García, A., «Los principios de transparencia, eficacia, libertad y legalidad en la Directiva 2013/11/UE del Parlamento Europeo y del Consejo de 21 de mayo de 2013, relativa a la resolu- 
Habida cuenta que la DRAL queda concebida como una Directiva de mínimos, los estándares aplicados a las entidades RAL pueden ser, a su vez, elevados en cada Estado miembro. A la hora de realizar la transposición de la DRAL casi todos los Estados han optado por incorporar las innovaciones del Derecho europeo manteniendo las estructuras de entidades RAL existentes ${ }^{26}$. Este modo de proceder ha sido posible como consecuencia de los márgenes muy amplios que la DRAL y el RRLL conceden a los Estados para su desarrollo. Desde esta perspectiva, ambos instrumentos vienen informados por un principio de respeto a la cultura jurídica y de invasión mínima en las tradiciones de los Estados miembros.

Para la DRAL resulta indiferente que los Estados miembros garanticen la cobertura material y territorial completa a través de una única, de varias o de múltiples entidades RAL. Tampoco se contienen opciones respecto del tipo de entidades, públicas o privadas, incluso con ánimo de lucro, con las que se va a garantizar la cobertura completa, ni un procedimiento a seguir. Por ejemplo, se concede a los Estados un margen amplio de libertad para la transposición en lo que respecta a las cuestiones de procedimiento que contempla el art. 5.4 DRAL, donde contará sobre todo el juicio de oportunidad que haga cada Estado. A su vez, dentro de cada Estado, es posible que las entidades RAL acreditadas tengan diferentes normas de procedimiento. En este punto la regulación europea se distancia de la legislación que se proyectó en el seno de la CNUDMI y del sistema seguido por la plataforma ECODIR, donde se concebía un procedimiento único y especial para las reclamaciones transfronterizas.

El Derecho europeo no obliga a los Estados a exigir la participación obligatoria, de empresas o consumidores, en procedimientos ante entidades RAL, ni tampoco a tomar una opción concreta entre los diferentes métodos de solución existentes. Desde esta perspectiva resultan compatibles con la DRAL los procedimientos que finalizan con una decisión que no posee carácter vinculante para ninguna de las partes, o cuyo carácter vinculante proviene de su aceptación ${ }^{27}$. Los Estados también pueden optar por atribuir a la decisión de la entidad RAL carácter vinculante exclusivamente para el empresario $^{28}$. La DRAL también ofrece respaldo a los sistemas de arbitraje de consumo, así como a aquellos en los que el carácter vinculante de la solución

ción alternativa de litigios de consumo, y su incidencia en el sistema de arbitraje de consumo español», en Palao Moreno, G. (ed.), Los nuevos instrumentos europeos en materia de conciliación, mediación y arbitraje de consumo, su incidencia en España, Irlanda y el Reino Unido, Valencia, Tirant lo Blach, 2016, pp. 37-79.

${ }^{26}$ Para una aproximación a algunos de los modelos seguidos para la transposición de la DRAL, véase el informe preparado por CORTÉs, P. y ESTEBAN DE LA ROSA, F., «La normativa europea de resolución de conflictos de consumo y su transposición en España: una oportunidad para mejorar los derechos de los consumidores aprovechando las experiencias positivas en el Derecho comparado", Zaragoza, ADICAE, 2016.

27 Por ejemplo, el sistema de las negociaciones representativas que se lleva a cabo en Italia a través de la conciliazione paritetica, o las decisiones de los mediateurs de empresa franceses.

28 Es el caso de las decisiones de los ombudsman en el Reino Unido y en Irlanda. 
deriva de su valor contractual ${ }^{29}$. Así se desprende del art. 2.4 DRAL en cuanto se faculta a los Estados miembros a admitir que los procedimientos ante entidades RAL finalicen con una decisión vinculante. Encuentran también encaje en la DRAL las entidades RAL que optan por métodos de solución mixtos, que comportan la combinación de métodos de carácter consensual y adjudicativo. El Derecho europeo solo excluye los métodos de solución en los que convergen dos circunstancias, a saber, el carácter obligatorio de la participación en el procedimiento ante una entidad RAL y el carácter vinculante de la decisión o, más exactamente, el hecho de que la decisión cierre la vía judicial ${ }^{30}$. No todos los métodos de solución han sido acogidos por los Estados miembros para ser empleados por sus entidades acreditadas. Países como Alemania o Italia, donde el arbitraje de consumo es bien conocido, solo permiten el acceso al proceso de acreditación a aquellas entidades RAL que no imponen una solución, lo que explica que los legisladores de estos dos países no hayan llevado a cabo la transposición de los arts. 10 y 11 DRAL. En cambio, en otros países, el método del arbitraje de consumo es expresamente previsto para sus entidades acreditadas ( $a d$. ex. Bélgica, Portugal, Irlanda, Reino Unido). No todas las entidades RAL existentes en los Estados miembros han obtenido, o están en proceso de obtener, la acreditación europea.

\section{3. ÁMBITO DE APLICACIÓN DEL NUEVO DERECHO EUROPEO}

De precisar el ámbito de aplicación del nuevo Derecho europeo se ocupa el apartado primero del art. 2 DRAL. Esta «se aplicará a los procedimientos de resolución extrajudicial de litigios nacionales y transfronterizos relativos a obligaciones contractuales derivadas de contratos de compraventa o de prestación de servicios entre un comerciante establecido en la Unión y un consumidor residente en la Unión, mediante la intervención de una entidad de resolución alternativa de litigios que propone o impone una solución o que reúne a las partes con el fin de facilitar una solución amistosa». Conviene recordar que, conforme al art. 4.1.h) DRAL, por entidad de resolución alternativa se entiende «toda entidad, establecida de manera duradera, que ofrece la resolución de litigios mediante un procedimiento de resolución alternativa y que está incluida en la lista con arreglo al art. 20, apartado 2». La RRLL solo incluye en su ámbito de aplicación a las reclamaciones surgidas del comercio en línea. Por tanto, sin perjuicio de las posibles disfunciones ( $a d$. ex. el consumidor consigue el correo del empresario, burla a la máquina en el paso correspondiente y el empresario no pone objeción), no puede ser utilizada para la presentación de otra clase de reclamaciones.

${ }^{29}$ Este sistema es el seguido por entidades RAL holandesas.

${ }^{30}$ Esta interpretación se desprende del art. 1 in fine y art. 10.2 DRAL. Por esta razón cabe plantear la duda relativa a la compatibilidad con los métodos admitidos por la DRAL del arbitraje obligatorio contemplado en el sistema portugués para el ámbito de los servicios esenciales. Véase la Lei 6/2011, dos serviços públicos essenciais, de 10 de marzo. Diário da República núm. 49/2011, Série I de 2011-03-10. 
Las exclusiones se contienen en el apartado segundo, que adoptan perspectivas muy diferentes, lo que dificulta la comprensión de su alcance. Resulta claro que para cumplir con la obligación que deriva del art. 5 DRAL de ofrecer una cobertura completa por entidades RAL, los Estados miembros no pueden apoyarse en entidades que no sean independientes del empresario reclamado, salvo que esta posibilidad haya sido expresamente autorizada, lo que ha ocurrido en el sistema francés. No reviste dificultad afirmar que la acreditación de una entidad RAL queda sometida a la condición de que esté establecida de manera duradera, de que pueda conocer de litigios relativos a obligaciones contractuales derivadas de contratos de compraventa o de prestación de servicios y de que dé cabida a las reclamaciones que se produzcan entre un empresario con establecimiento en la UE y un consumidor residente en la UE. Como consecuencia, no es posible que un Estado conceda la acreditación a una entidad RAL que no pueda conocer de esta clase de litigios ${ }^{31}$. En cambio, no existe problema para conceder la acreditación a entidades RAL cuya competencia se extienda sobre el conocimiento de litigios que no estén incluidos en el ámbito de aplicación de la DRAL, siempre y cuando también la posean para conocer de los primeros.

La intención de las exclusiones recogidas en las letras $h$ ) e i) del art. 2.2 DRAL es reducir el alcance de las obligaciones que pesan sobre los Estados de garantizar una cobertura completa por entidades RAL de los litigios relativos a contratos de prestación de esos servicios, por lo que nada obsta a extender sobre ellos la cobertura de las entidades RAL acreditadas. En Europa contamos ya con el precedente del Reino Unido, donde la referida extensión ha tenido lugar debido a que los estudiantes universitarios son considerados como consumidores. Una lectura similar merecen las exclusiones contenidas en las letras d) y g). Resulta de interés traer a colación el sentido originario de la letra $g$ ) (procedimientos iniciados por un comerciante contra un consumidor) en la tramitación del texto que fue presentado por la Comisión Europea. $\mathrm{Al}$ inicio se observó que muchas empresas no se adherían voluntariamente a los sistemas de resolución alternativa de litigios de consumo y se pensó que un buen modo de atraerlas podría consistir en obligar a las entidades RAL a conocer también de las reclamaciones presentadas por empresarios. Esta idea decayó muy tempranamente por entenderse que la mayoría de los servicios de resolución alternativa de litigios de consumo tienen una orientación hacia la protección del consumidor y, por tanto, poner a las empresas en pie de igualdad respecto de los consumidores ante las entidades de resolución alternativa de litigios de consumo desnaturalizaría la razón de ser de estas entidades, financiadas en muchas ocasiones de forma pública. Por tanto, leída de este modo, la exclusión tiene por finalidad aclarar que una entidad RAL podrá acceder a la acreditación a pesar de que solo permita la presentación

31 En el sistema español, cabe, por ejemplo, mencionar al jurado de la publicidad denominado AUTOCONTROL. Se trata de una entidad que fue notificada a la Comisión Europea como cumplidora de los principios contenidos en las Recomendaciones de 1998 y 2001 que, sin embargo, no tiene competencia para conocer de litigios de tipo contractual. 
de reclamaciones por parte de los consumidores. Ello no obsta a la posibilidad de conceder la acreditación a entidades que permitan las reclamaciones en ambos sentidos. Esta interpretación queda avalada por la previsión que contiene el art. 2.2 RRLL, que autoriza el uso de la plataforma para estas reclamaciones. De hecho, algunos Estados miembros, como Alemania, Bélgica, Luxemburgo y Polonia, contemplan que las entidades RAL puedan conocer de las reclamaciones de un comerciante contra un consumidor.

Es sabido que la DRAL ha acogido como estándares de calidad mínimos para las entidades RAL acreditadas aquellos que fueron recopilados por las recomendaciones de 1998 y $2001^{32}$. Sin embargo, el alcance de los principios proclamados (conocimientos especializados, independencia, imparcialidad, transparencia, eficacia, equidad, libertad y legalidad) tampoco resulta manifiesto de la lectura de la DRAL. Para la gran mayoría de la doctrina ha de entenderse que estos principios son obligatorios para aquellas entidades RAL que hayan accedido a la acreditación europea.

Sin embargo, esta interpretación no puede ser referida a la garantía jurídica enunciada bajo el principio de libertad, conforme a la cual queda excluido el efecto vinculante para el consumidor de un pacto que le prive del derecho a recurrir a tribunales y que haya sido celebrado antes de que surja el litigio. Limitar el alcance de esa garantía exclusivamente a aquellos supuestos donde la cláusula de sumisión remite a una entidad RAL acreditada, comporta el establecimiento de dos regímenes diferentes para las cláusulas de arbitraje de consumo en dependencia del carácter de la entidad designada. El problema interpretativo se desvanece cuando se comprueba que el principio de libertad es una garantía concedida por la DRAL a los consumidores con residencia en un Estado miembro. Viene aquí también a colación la interpretación que hemos propuesto para la letra g) del art. 2.2 DRAL (litigios iniciados por el comerciante contra el consumidor), pues de acuerdo con una interpretación cabría entender que el art. 10 DRAL no es de aplicación cuando la reclamación ha sido presentada por el comerciante ${ }^{33}$. Esta comprensión, sin embargo, no solo no se compadece con el objetivo de la exclusión, sino que conduciría al resultado de dotar a la cláusula arbitral de un régimen diferente dependiendo de cuál sea la posición, de demandante o de demandado, que asuman, consumidor y empresario, en cada caso, algo que no puede haber estado en la intención del legislador europeo.

32 Véanse la Recomendación 98/257/CE de la Comisión, relativa a los principios aplicables a los órganos responsables de la solución extrajudicial de los litigios en materia de consumo, DO L núm. 115, de 17 de abril de 1998; y la Recomendación 2001/310/CE de la Comisión, relativa a los principios aplicables a los órganos extrajudiciales de resolución consensual de litigios en materia de consumo, DO L núm. 109, de 19 de abril de 2001.

33 Véase, por ejemplo, Reich., N., "A Trojan Horse in the Access to Justice - Party Autonomy and Consumer Arbitration in Conflict in the ADR-Directive 2013/11/EU?», ERCL, vol. 10, 2014, núm. 2, pp. 269-270. Quisiéramos cumplimentar nuestro sentido afecto al autor citado, jurista como pocos y cuya especial sensibilidad en el ámbito del Derecho europeo de la protección del consumidor siempre fue un placer seguir. Lamentablemente nos ha dejado hace pocas fechas, por lo que quisiéramos brindar este estudio a modo de humilde homenaje a su memoria. 
De la lectura de la DRAL tampoco resulta fácil dilucidar el alcance de las obligaciones que asigna a los empresarios el art. 13 relativas a informar sobre las entidades RAL a las que se encuentran adheridos o en cuyos procesos están obligados a participar. Según la interpretación más al uso, que toma como fundamento el art. 4.1.h) DRAL, esta obligación solo existiría cuando la entidad RAL en cuestión haya obtenido la acreditación europea, de tal manera que los empresarios adheridos a entidades RAL no acreditadas no quedarían obligados a informar a los consumidores sobre su adhesión. Sin perjuicio de que los Estados, en su legislación, pueden hacer extender la obligación sobre tales empresarios, el carácter externo de este deber de información respecto a la configuración de las entidades RAL hace posible mantener que, en realidad, la DRAL asigna este deber a todos los empresarios, en todo el ámbito de aplicación a que se refiere el art. 2.1 DRAL.

\section{RÉGIMEN DE LA RESOLUCIÓN ALTERNATIVA DE LITIGIOS DE CONSUMO TRANSFRONTERIZOS}

\subsection{Relaciones con las normas de competencia judicial internacional}

La DRAL no contiene normas sobre competencia internacional de las entidades RAL para conocer de los asuntos transfronterizos, ni tampoco una remisión al Reglamento Bruselas I bis, de manera análoga a la remisión que hace el art. 11 DRAL al art. 6 del Reglamento Roma I. En favor de la preterición de estas reglas de competencia internacional cabe argüir el carácter voluntario, por regla general, del sometimiento del consumidor al procedimiento ante una entidad RAL, a quien le corresponde la apertura de la reclamación. A este argumento cabe replicar fácilmente que, en la práctica, el consumidor poco tiene que decir al respecto pues es la empresa quien está obligada a participar ante el procedimiento ante una concreta entidad RAL o, en su caso, ha elegido a una entidad RAL que le pueda ser más benévola que, en los supuestos transfronterizos, incluso puede ser la de un Estado diferente al de la residencia del consumidor y del establecimiento de la empresa.

En los procedimientos ante entidades RAL que finalizan con una decisión no vinculante para el consumidor este mantiene intacta la posibilidad de acudir a la vía judicial, por lo que no perdería la opción de los foros especiales de protección del consumidor contenidos en el Reglamento Bruselas I bis. En la visión seguida por la DRAL, la garantía que supone para el consumidor participar en un proceso que obliga a la entidad RAL a informarle, de acuerdo con el principio de equidad, de que puede dar por terminado el procedimiento en cualquier momento, de que tiene la opción de aceptar o rechazar la solución propuesta, de que la solución propuesta puede ser distinta del resultado determinado por un órgano jurisdiccional que aplique normas jurídicas, y que obliga también a la entidad RAL a otorgar a las partes, antes de dar su consentimiento a una solución propuesta o a un acuerdo amistoso, un pla- 
zo de reflexión razonable (art. 9 DRAL), son considerados como elementos de protección suficientes para compensar la pérdida de la vía judicial. Esta regulación de la DRAL creemos que no resulta completamente satisfactoria para los supuestos transfronterizos. En un supuesto doméstico poco cabe reprochar a este silogismo. Pero en uno transfronterizo, en el que la tramitación de la reclamación tendrá probablemente lugar en un idioma extranjero para el consumidor, la regulación ofrecida por el Derecho europeo no ofrece garantías suficientes, lo cual va en detrimento del derecho de acceso a tribunales. Por ello resulta necesario exigir que la información importante de cara a la preservación del derecho del consumidor de proseguir un procedimiento por la vía judicial, en muchas ocasiones ante los jueces de su domicilio, haya de ser objeto de una traducción específica a fin de que se garantice que sea facilitada, siempre y en todo caso, en el idioma del consumidor o, al menos, en el idioma en el que ha sido presentada la reclamación.

Para los casos en los que la decisión que pone punto y final al procedimiento resulta vinculante para el consumidor la DRAL contempla dos elementos adicionales de protección del consumidor en los arts. 10 y 11. Por una parte, se obliga a los Estados a garantizar el carácter no vinculante para el consumidor de una cláusula arbitral contenida en un acuerdo celebrado antes de que surja el litigio. Por la otra, se obliga a los Estados a garantizar la aplicación por las entidades RAL de las normas imperativas de protección del consumidor. En la mayoría de las entidades RAL de los Estados miembros la presentación de reclamaciones corresponde en exclusiva a los consumidores. Esta circunstancia se alinea de forma positiva con el régimen del art. 10 DRAL puesto que, en ese caso, el convenio cumplirá con el requisito de haber sido celebrado con posterioridad al surgimiento del litigio. Por ello resulta legítimo plantear si con la cautela del art. 10 DRAL resulta suficiente para dar respuesta satisfactoria a las exigencias que derivan del derecho a la tutela judicial efectiva reconocido por el art. 47.1 CEDF y el art. 19 TUE $^{34}$. Por ejemplo, en opinión del Profesor Norbert Reich, la incorporación del arbitraje de consumo al sistema europeo de entidades RAL provoca una desactivación desafortunada del marco de protección previsto por los foros especiales para la materia de los contratos celebrados por los consumidores.

Resulta difícil valorar en este momento si las garantías que ofrece la DRAL para los supuestos de arbitraje de consumo (principio de libertad y de legalidad) son suficientes para dar respuesta a las exigencias de los derechos fundamentales mencionados; si con ulteriores garantías dicho método sería aceptable; o si este método ha de ser considerado en contradicción con ellos. Si bien es cierto que existen razones para poner en duda la idoneidad del arbitraje como método para la resolución de litigios de consumo ${ }^{35}$, el hecho

\footnotetext{
${ }^{34}$ Ibid., pp. 258-280.

35 Estas críticas se pueden resumir en cuatro puntos. En primer lugar, los beneficios que proporciona en términos de ejecutividad de la decisión pierden gran parte de su significado como consecuencia del alto porcentaje de cumplimiento voluntario de las decisiones; en segundo lugar, el arbitraje implica el sometimiento del litigio a normas rígidas de procedimiento que no favorecen la resolución
} 
de que este método sea utilizado en muchos Estados miembros y de que la DRAL le haya dado respaldo en el nuevo Derecho europeo es algo que no se puede ignorar. Ahora bien, en aras de la optimización de los derechos mencionados, merecerá la pena considerar la incorporación al Derecho europeo de garantías adicionales. A este fin resultan adecuadas las propuestas que se cifran en someter la validez del acuerdo arbitral a tribunales, dejando al margen en este ámbito la regla según la cual corresponde al órgano arbitral decidir sobre su competencia, y en permitir la impugnación del laudo por infracción de normas imperativas de protección del consumidor. Pero puede haber más, como las relacionadas, como veremos, con la facilitación al consumidor, en su propio idioma o en el idioma de presentación de la reclamación, al menos de aquella información mínima que sea de relevancia para poder mantener el derecho de acudir a la vía judicial.

Las finalidades de la plataforma europea no guardan relación con los criterios de competencia judicial internacional para los contratos de consumo. Ello explica que la admisión de reclamaciones transfronterizas a través de la plataforma europea no quede sometida a los mismos principios de las reglas de competencia de los contratos celebrados por consumidores. El uso de la plataforma está reservado para las reclamaciones procedentes de compras de bienes y servicios en línea. En cambio, para determinar la operatividad del foro del domicilio del consumidor hay que tener en cuenta «si, antes de la celebración del contrato con el consumidor, de las citadas páginas web y de la actividad global del vendedor se desprendía que este último tenía intención de comerciar con consumidores domiciliados en otro u otros Estados miembros, entre ellos el del domicilio del consumidor, en el sentido de que estaba dispuesto a celebrar contrato con ellos» ${ }^{36}$. Sin perjuicio de la finalidad diversa, creemos que hay razones para proponer la conveniencia de habilitar la utilización de la plataforma RLL, en el caso de las reclamaciones transfronterizas, también a los consumidores que tengan derecho a la utilización del privilegio procesal. De este modo, se evitaría la necesidad de considerar un elemento fortuito, y de difícil prueba, como la realización del encargo a través de la Red. Por otra parte, con el criterio ahora acogido, los consumidores "pasivos» que no hayan realizado el encargo a través de la Red no disponen de la opción de utilizar la plataforma para presentar sus reclamaciones, una opción que ayudaría a evitar la presentación de una reclamación judicial ante los tribunales de su domicilio.

de los casos; en tercer lugar, el método del arbitraje impide por definición el diálogo entre las partes para tratar de encontrar una solución, lo que puede provocar decisiones con ganador y perdedor; por último, detrás del arbitraje no hay otra cosa que la renuncia a tribunales, a quienes corresponde la garantía última del cumplimiento de las normas imperativas de protección del consumidor.

36 STJ de 7 de diciembre de 2010, asuntos C-585/08 y C-144/09, ECLI:EU:C:2010:740. Véanse también las decisiones del TJ de 6 de septiembre de 2012, asunto C-190/11, ECLI:EU:C:2012:542, y de 17 de octubre de 2013, asunto C-218/12, ECLI:EU:C:2013:666. Véase un comentario a esta decisión en Esteban DE LA Rosa, F., «El papel del nexo de causalidad en el sistema europeo de competencia internacional de los contratos de consumo: ¿Una condición para el olvido?», La Ley Unión Europea, mes 11, 2014, pp. 5-17. 


\subsection{Cambios en la gestión de las reclamaciones transfronterizas derivados del nuevo marco institucional}

Aunque también es de aplicación a las reclamaciones domésticas, el completo diseño del marco institucional creado encuentra explicación en las necesidades especiales de las reclamaciones transfronterizas. La mayor innovación del Derecho europeo es la creación y puesta en marcha de la plataforma europea de resolución en línea de litigios de consumo. Los consumidores residentes en un país miembro de la Unión Europea pueden presentar sus reclamaciones vía Internet en la web gestionada por la Comisión Europea, que serán dadas a conocer al empresario reclamado y transmitidas, en su caso, para ser tramitadas, a una entidad RAL de un Estado miembro.

Sin embargo, hay que tener presente que la disponibilidad de la plataforma es limitada. En primer lugar, en ella solo se pueden presentar las reclamaciones de consumidores residentes en la UE contra empresas establecidas en un Estado miembro. De lo contrario, a través de los datos sucesivos que requiere la propia plataforma en el momento de presentar la reclamación, esta posibilidad queda excluida. En principio, ante unos datos falsos aportados por el consumidor ( $a d$. ex. reside en Marruecos pero indica que reside en España) no refutados por el empresario, parece difícil que la Comisión Europea pueda decretar el archivo del caso una vez que haya sido transmitido a una entidad RAL con el acuerdo de ambas partes. Esta entidad RAL, salvo que disponga de normas que limiten su competencia territorial, que no suelen ser frecuentes, tampoco detendrá su actuación. En segundo lugar, como hemos visto, la plataforma solo admite las reclamaciones procedentes del comercio en línea (art. 2.1 RRLL).

Otro de los cambios en el tratamiento de las reclamaciones transfronterizas de consumo consiste en que las nuevas entidades RAL acreditadas no pueden rechazar el conocimiento de una reclamación transfronteriza, para por ejemplo reenviarla al $\mathrm{CEC}^{37}$. De hecho, esta es la operativa que está siendo seguido por la mayoría de las entidades RAL españolas, entre ellas las Oficinas Municipales de Información al Consumidor (en adelante OMIC), cuando se enfrentan a una reclamación de ese tipo. A través de los CEC es posible localizar a la entidad RAL competente en el país del empresario para resolver la reclamación, o incluso se lleva a cabo cierta actividad de mediación. La asimilación que propone la DRAL entre reclamaciones transfronterizas y domésticas determina que sobre las nuevas entidades RAL acreditadas recaiga la obligación, más compleja, de gestionar las reclamaciones transfronterizas. Esta mayor complejidad se presenta como consecuencia de que

37 Conviene advertir que esta transmisión a los CEC tenía lugar de facto, pues la mayoría de las entidades RAL existentes en España no explicitaban el alcance de su competencia sobre los litigios transfronterizos. La excepción la encontramos en el Reglamento de Confianza Online. Véase la página web https://www.confianzaonline.es/consumidores/guia-practica-de-consumidores-faq/ (consultada el 5 de diciembre de 2016). 
el consumidor no dominará en muchos casos el idioma en el que se sigue el procedimiento y el gestor del caso también deberá enfrentarse a documentos en idioma extranjero. La DRAL no obliga sin embargo a las entidades RAL estatales al empleo de todos los idiomas, sino simplemente a hacer público los idiomas en que será posible tramitar las reclamaciones.

Junto a estos elementos, la DRAL contiene disposiciones que sirven a las necesidades especiales de las reclamaciones transfronterizas, como la obligación de facilitar información sobre la participación de la entidad RAL en redes de entidades de resolución alternativa que facilitan la resolución de litigios transfronterizos [art. 7.1.e) DRAL], sobre las lenguas en las que pueden presentarse las reclamaciones a una entidad de resolución alternativa y en las que se desarrolla el procedimiento de resolución alternativa [art. 7.1.h) DRAL] y sobre la cooperación de las entidades de resolución alternativa en redes de entidades de resolución alternativa que facilitan la resolución de litigios transfronterizos, en su caso [art. 7.2.h) DRAL]. Para el caso de reclamaciones transfronterizas se obliga a los Estados a habilitar puntos donde los consumidores puedan obtener asistencia para acceder a la entidad de resolución alternativa que opere en otro Estado miembro y a velar porque las entidades RAL cooperen en la resolución de litigios transfronterizos (art. 16 DRAL). Dado que en algunos Estados miembros las entidades RAL pueden conocer de litigios presentados por los empresarios contra los consumidores, el RRLL prevé la posibilidad de que sea usada la plataforma para canalizar estas reclamaciones, siempre que la ley del país de la residencia del consumidor así lo permita.

\subsection{Cuestiones de Derecho aplicable}

\subsubsection{Los modos de prestación del consentimiento para el inicio del procedimiento ante una entidad $R A L$}

El nuevo sistema europeo permite que las reclamaciones sean presentadas por tres vías, a saber, directamente ante una entidad RAL extranjera sin utilizar el recurso en línea ${ }^{38}$, a través de la utilización del acceso en línea que está obligada a habilitar cada entidad RAL acreditada ${ }^{39} \mathrm{y}$, por último, la que se supone que será preferida por permitir el empleo del idioma del consumidor, mediante la utilización de la plataforma europea de resolución en línea de litigios de consumo. En todos los casos el presupuesto para la actuación de la entidad RAL es la existencia de una obligación legal de participar, un acuerdo válido entre las partes o una combinación de ambas ${ }^{40}$.

\footnotetext{
38 Véase el art.5.2.c) DRAL.

39 Véase el art. 5.2.a) DRAL.

40 Dejamos al margen la posibilidad de presentar la reclamación ante los Centros Europeos del Consumidor en la forma que se ha venido haciendo hasta ahora. Si bien es cierto que con la entrada en vigor del Reglamento RRLL los Centros Europeos del Consumidor han asumido funciones específicas
} 


\subsubsection{Ley aplicable al sometimiento a entidades $R A L$ : régimen general}

La DRAL no proporciona un régimen para la validez internacional de los pactos de sumisión a entidades RAL, por lo que hay que recurrir a las reglas generales de Derecho internacional privado. Este régimen depende fundamentalmente del método de solución empleado por la entidad RAL. Cuando el procedimiento ante la entidad RAL no finaliza con una decisión vinculante para ninguna de las partes, por seguirse un procedimiento de mediación o de conciliación, se impone una calificación contractual, de tal manera que será de aplicación el Reglamento Roma I a los litigios relativos a la validez e interpretación del acuerdo de sometimiento a mediación ${ }^{41}$. El Reglamento Roma I también se aplica para determinar la validez del acuerdo en virtud del cual las partes se someten a la decisión vinculante de un tercero que no posea más que fuerza contractual, y no arbitral, tal y como sucede en algunas entidades RAL existentes en Holanda. Esta misma ley es de aplicación para decidir sobre la incorporación al contrato de una cláusula contenida en un clausulado general de la contratación, incluso contenido en los términos y condiciones de una página web, que el consumidor ha aceptado en el momento de la celebración del contrato que ha dado origen a la reclamación. En este caso podrá cobrar relevancia la invocación de la ley del país de la residencia habitual en conformidad con el art. 10.2 del Reglamento Roma I cuando, conforme al Derecho de ese país, no sea posible asociar al comportamiento de esa parte el efecto de prestar su consentimiento. La emisión de declaraciones de voluntad a través de medios electrónicos hoy no reviste graves dificultades pues la mayoría de los sistemas estatales han acogido esta posibilidad. En el ámbito de la Unión Europea el art. 9 de la Directiva sobre comercio electrónico impone a los Estados la obligación de no entorpecer la utilización de la vía electrónica ${ }^{42}$.

En ocasiones las empresas, todas o las de un concreto sector de actividad, quedan obligadas a participar en el procedimiento ante una entidad RAL o incluso a aceptar su decisión. Los supuestos de arbitraje obligatorio en el ámbito de los servicios esenciales bajo el sistema portugués es paradigmática de esta opción. Para tales casos podrá ser necesario comprobar el alcance de esta obligación legal. Para determinar la validez de la adhesión del consumidor sigue siendo de aplicación el Reglamento Roma I, lo que queda facilitado al formar parte también de la materia contractual los supuestos en los que cabe identificar una obligación jurídica libremente consentida por una perso-

relacionadas con la gestión de las reclamaciones, sin embargo, las funciones que tenían hasta ahora no han sido modificadas. Véase la información disponible en la web http://www.cec.consumo-inc.es/ secciones.php?id_sec=5\&id_subsec=16 (consultada el 3 de diciembre de 2016).

41 En este sentido, véase Esplugues MотA, C., «El régimen jurídico de la mediación civil y mercantil en conflictos transfronterizos en España tras la Ley 5/2012, de 6 de julio», Boletín Mexicano de Derecho Comparado, nueva serie, año XLVI, enero-abril de 2013, núm. 136, pp. 181-182.

42 Lara Aguado, A., «La formación del contrato de consumo electrónico», en Esteban dE La Rosa, F. (ed.), La protección del consumidor en dos espacios de integración: Europa y América, Valencia, Tirant lo Blanch, 2015, pp. 285-286. 
na respecto a otra $^{43}$. Ni la DRAL ni el sistema general definen la ley a la que corresponde decidir en torno a la existencia de una eventual obligación legal de adhesión al procedimiento ante una entidad RAL. De forma implícita, la DRAL apunta a la ley del país del establecimiento de la empresa ${ }^{44}$. Pero no es algo que realmente esté regulado, y ni siquiera los Estados se han ocupado de definir, de forma unilateral, el alcance de estas obligaciones. La existencia de un volumen importante de actividad de una empresa en un país distinto al de su establecimiento podría proporcionar argumentos para extender sobre tales empresas las mencionadas obligaciones. En tal caso habrá que esperar para determinar si tal extensión ha de ser considerada como una restricción injustificada a la libre prestación de servicios reconocida por el Derecho europeo.

Por otra parte, aunque pueda resultar extraño, en algunos sistemas el consumidor es obligado a participar en un procedimiento de mediación preceptivo para poder emprender acciones judiciales. Esta posibilidad ha quedado abierta tras la decisión del TJ de 18 de marzo de 2010 dictada en el asunto Alassini $^{45}$. La DRAL no se pronuncia sobre cuál ha de ser la ley aplicable para determinar si el consumidor ha de quedar sometido a esta mediación de carácter obligatorio. A la vista del carácter procesal de la cuestión, y de los efectos que esta mediación posee, fundamentalmente, sobre el proceso posterior, resulta difícil excluir una calificación de ese tipo y la aplicación del Derecho del foro. Sin embargo, la desigualdad existente en Europa en torno a esta cuestión, y la posibilidad de dar una mejor respuesta a la expectativa del consumidor con residencia fuera del país del foro, podría alinearse a favor de acoger la aplicación de la ley del país de la residencia habitual del consumidor. De esta manera, cabría seguir un criterio de protección análogo al establecido en el art. 2.2 RRLL para decidir si es posible que el empresario reclame contra el consumidor a través de la plataforma europea.

Los problemas de validez del convenio arbitral en reclamaciones transfronterizas quedan en cambio sometidos al Convenio sobre reconocimiento y ejecución de sentencias arbitrales extranjeras, hecho en Nueva York el 10 de junio de 1958 (en adelante CNY) ${ }^{46}$. El art. II exige la existencia de un acuerdo por escrito y fija las condiciones en que este requisito se entiende satisfecho a través de un régimen mixto compuesto, por un lado, de una regulación uniforme y, por otro, de una remisión al Derecho nacional aplicable según la norma de conflicto contenida en el art. V.1.a) del $\mathrm{CNY}^{47}$.

43 Véanse las SSTJ de 20 de enero de 2005, asunto C-27/02, ECLI:EU:C:2005:33, y de 14 de marzo de 2013, asunto C-419/11, ECLI:EU:C:2013:165.

44 Véase, por ejemplo, el art. 13 DRAL.

45 Asuntos C-317/08, C-318/08, C-319/08 y C-320/08, ECLI:EU:C:2010:146. En la actualidad estamos a la espera de que el TJ se pronuncie sobre la conformidad con el Derecho europeo de una mediación obligatoria para el consumidor en la que este ha de soportar el coste de ser asistido de letrado antes de emprender acciones judiciales. Se trata de la cuestión prejudicial C-75/16, planteada el 10 de febrero de 2016 por el Tribunal Ordinario de Verona.

46 BOE núm. 164, de 11 de julio de 1977.

47 Sobre la interpretación que ha de hacerse del convenio de Nueva York a fin de convertir la norma sobre reconocimiento del art. $\mathrm{V}$ en una norma de conflicto referida a la validez del convenio arbi- 
Respecto de las reclamaciones que sean presentadas ante la plataforma europea, o también eventualmente a través del recurso electrónico habilitado por una entidad RAL estatal de arbitraje de consumo, el cumplimiento de los requisitos no ha de revestir excesiva dificultad, a pesar de la exigencia del acuerdo por escrito. La proliferación del comercio electrónico, y el uso frecuente de cláusulas arbitrales en correos electrónicos o en sitios web interactivos, tales como la plataforma europea, ha motivado que, también en este ámbito, se proponga la asimilación entre ambos tipos de comunicaciones ${ }^{48}$. Habida cuenta del régimen protector que incorpora el art. 10 DRAL, según el cual el pacto ha de ser posterior al surgimiento del litigio, será difícil que aparezca la oportunidad de dar validez a un acuerdo de arbitraje contenido en condiciones generales de la contratación. Si fuera el caso, para la incorporación de la cláusula al contrato será de aplicación el propio sistema del $\mathrm{CNY}^{49}$.

El orden público es un límite con el que tradicionalmente ha contado el acuerdo arbitral en presencia de consumidores. En estos casos la validez de los acuerdos arbitrales ha solido ser impugnada desde dos frentes, a saber, el de las cláusulas abusivas ${ }^{50}$ y el de la imposibilidad de desactivar los foros de protección del consumidor mediante la sumisión a un arbitraje extranjero ${ }^{51}$. Como vamos a ver la entrada en vigor del nuevo sistema europeo hace necesario reformular el modo en que operan ambos límites de orden público, determinando la necesidad de definir la relación entre el régimen de las cláusulas abusivas y el que proviene del art. 10 DRAL, por una parte, y la necesidad de superar la interpretación seguida en el otro caso pues, de otro

tral, véase VIRgós Soriano, M., «El convenio arbitral en el arbitraje internacional», Actualidad Jurídica Uría Menéndez, vol. 14, 2006, pp. 16-21.

48 En este sentido, véase Fernández Rozas, J. C., Arenas García, R. y de Miguel Asensio, P., Derecho de los negocios internacionales, Madrid, Iustel, 2. ${ }^{\text {a }}$ ed., 2009, p. 655. La proliferación de los convenios arbitrales electrónicos contenidos en contratos celebrados en línea, y la falta de certeza que puede existir respecto de su validez y eficacia en todas las jurisdicciones, ha hecho preciso que el organismo que elaboró el convenio de Nueva York, Naciones Unidas, haya puesto su atención en este tema. Una primera actuación ha consistido en la elaboración de una Recomendación relativa a la interpretación del párr. 2) del art. II y del párr. 1) del art. VII de la Convención de Nueva York, de 10 de junio de 1958, adoptada por la Comisión de las Naciones Unidas para el Derecho Mercantil Internacional el 7 de julio de 2006 en su $39 .^{\circ}$ periodo de sesiones, donde, teniendo en cuenta la posibilidad del convenio arbitral electrónico, se recomienda considerar que no son exhaustivas las circunstancias que describe el párr. 2 del art. II del Convenio de Nueva York. La segunda se refiere a la regulación proyectada, pues la Convención sobre la Utilización de las Comunicaciones Electrónicas en los Contratos Internacionales, que ha sido aprobada por la Asamblea General de Naciones Unidas, incluye en su art. 20 una disposición que hace extensiva su regulación al convenio de Nueva York de 1958. En cualquier caso, la posibilidad de recuperación a efectos de prueba es lo que dota al convenio arbitral electrónico de su equivalencia con el celebrado en soportes tradicionales. A este fin responde, entre los medios de prueba, la firma electrónica, dado que permite efectuar la comprobación de la identidad del origen y de la integridad de los mensajes intercambiados en Internet.

49 Véase Virgós Soriano, M., op. cit., nota 47, pp. 16-21.

50 Es sabido que la legislación de muchos Estados miembros considera inválidos, por abusivos, a los pactos arbitrales de consumo celebrados antes del surgimiento del litigio. Véase la información contenida en Cortés, P. y Esteban de la Rosa, F., «Building a Global Redress System for Low Value Cross-Border Disputes», International and Comparative Law Quarterly, vol. 62, 2013, pp. 428-429.

51 Véase VIRgós Soriano, M., op. cit., nota 47, pp. 22-23. 
modo, se pone en cuestión el propio funcionamiento de la plataforma para las reclamaciones transfronterizas de consumo.

\subsubsection{La determinación del Derecho aplicable a la enervación del carácter vinculante para el consumidor del pacto de arbitraje de consumo}

La incidencia de la DRAL sobre el régimen del acuerdo de sometimiento de litigios a entidades RAL es solo parcial y no afecta a las cuestiones de validez, salvo en lo relativo a la exigencia especial de consentimiento informado. Cuando el pacto de sumisión a una entidad RAL ha sido celebrado antes del surgimiento del litigio y, sin embargo, dicho pacto no cierra la vía judicial, el régimen de validez y eficacia del pacto se mantiene, de forma intacta, sobre la ley aplicable hallada en la forma más arriba indicada. Ello no significa, pero es una cuestión distinta, que no pueda plantearse la conformidad con el Derecho europeo de un concreto sistema estatal ${ }^{52}$.

El interés mayor se encuentra en los casos en los que la resolución tiene carácter vinculante. El art. 10 DRAL declara que no serán vinculantes para el consumidor los pactos, celebrados antes del surgimiento del litigio, que tienen por efecto privar al consumidor de su derecho a recurrir a tribunales, lo que sucede singularmente con el arbitraje de consumo. Habida cuenta que la DRAL no goza de aplicación directa, en los casos de reclamaciones transfronterizas se hace necesario determinar cuál es el régimen jurídico aplicable a la posibilidad de enervar el carácter vinculante de un pacto de arbitraje de consumo celebrado con anterioridad al surgimiento del litigio. De esta cuestión no se ocupa la DRAL. A pesar de que la calificación contractual parece la más razonable, la aplicabilidad del Reglamento Roma I debe ser descartada, pues en su art. 1.1.e) excluye de su ámbito de aplicación «los convenios de arbitraje». Como consecuencia hemos de dirigirnos de nuevo al régimen del CNY, el cual se ocupa no solo de las cuestiones de validez del acuerdo arbitral sino también de su ineficacia o su inaplicabilidad (art. II.3). Conforme a la interpretación que es posible hacer del art. V.1 CNY, la cuestión queda sometida a la ley elegida por las partes y, en su defecto, a la ley del Estado en el que vaya a tener lugar el arbitraje ${ }^{53}$, lo que en el caso de las entidades RAL de consumo reconduce la cuestión a la ley del país de la sede de la entidad, de cuya concreción se ocupa el art. 4.3 DRAL.

Esta solución resulta sin embargo inadecuada, pues a través de la elección de la ley aplicable no se llega a garantizar la aplicación del Derecho de un Estado miembro, de tal manera que, a través de la designación del Derecho aplicable, puede llegar a ser inoperativa la regla europea según la cual el pacto de arbitraje de consumo no ha de ser vinculante para el consumidor cuando

\footnotetext{
52 Para lo cual resulta de interés conocer los criterios que han sido establecidos por el TJ en su decisión de 18 de marzo de 2010, asuntos C-317/08, C-318/08, C-319/08 y C-320/08, ECLI:EU:C:2010:146.

53 Véase Virgós Soriano, M., op. cit., nota 47, p. 21.
} 
ha sido celebrado con anterioridad al surgimiento del litigio. Aflora de este modo un ámbito en el que es necesario invocar el carácter de orden público de la regulación europea de protección del consumidor en la regulación del art. 10.1 DRAL. Para facilitar esta operación sería del mayor interés contar en la DRAL con una disposición a fin de obligar a los Estados a garantizar el carácter no vinculante del pacto arbitral para el consumidor en los supuestos transfronterizos, en un modo análogo al seguido por otras Directivas europeas. Una norma de este tipo será también de utilidad para los supuestos en los que la decisión de la entidad RAL pone carácter vinculante para las partes pero carece de los atributos del laudo arbitral.

\subsubsection{Régimen del consentimiento informado: cuestiones conflictuales y materiales}

El apartado segundo del art. 10 DRAL contiene una nueva exigencia que es de aplicación cuando la decisión de la entidad RAL resulta vinculante para las partes. Este efecto puede darse tanto en los supuestos de arbitraje de consumo como, también, cuando la decisión vinculante posee fuerza meramente contractual. El art. 10.2 DRAL incorpora un nuevo requisito de validez para el convenio arbitral. El régimen especial de consentimiento informado que se contiene en el art. 10.2 DRAL tampoco cuenta con criterios espaciales de aplicación por lo que, para la determinación del Derecho estatal aplicable cobran valor las mismas consideraciones que acabamos de hacer.

Finalmente, creemos necesario poner de relieve una exigencia que el mencionado requisito debería tener sobre la configuración de la prestación del consentimiento a través de la plataforma europea. Si bien el RRLL se refiere a la necesidad de que las partes acuerden en torno a la entidad RAL que conocerá de la reclamación (art. 6, apdos. 3 y 4), no se proporciona información sobre si se contempla, por parte de la plataforma, un modo especial de prestación del consentimiento que garantice el consentimiento informado a que se refiere el apartado segundo del art. $10 \mathrm{DRAL}^{54}$. A expensas de lo que pueda ser interpretado por el TJ, la garantía de dicho consentimiento aconseja habilitar la posibilidad de hacer clic en sendos botones que permitan declarar, por una parte, que se acepta el arbitraje como método de solución y, por otra, que el consumidor conoce que la decisión tendrá para él carácter vinculante. Dada la trascendencia de estas declaraciones, de las cuales deriva la renuncia a tribunales y, eventualmente, a la posibilidad de acogerse el consumidor a los foros del país de su domicilio, se debería exigir, en los supuestos transfronterizos, que tales declaraciones hayan de ser realizadas en el idioma del consumidor o, como mínimo, en el idioma en el que la reclamación fue presentada, no siendo suficiente que se arbitre la posibilidad de utilizar el idio-

54 Sin entrar en la cuestión, sí quisiéramos dejar constancia de la diferencia existente entre las versiones lingüísticas de la DRAL. Mientras que en la española o en la alemana lo que se requiere es una aceptación expresa, en la versión en lengua inglesa se exige una specific acceptance. 
ma en el que tuvo lugar la transacción que ha generado la reclamación. Esto tiene como consecuencia que, en los supuestos transfronterizos, la prestación del consentimiento debería admitirse solo a través de la plataforma europea. Debería excluirse por tanto la posibilidad de dar eficacia a una declaración de aceptación del arbitraje de consumo a través de plataformas habilitadas por entidades RAL extranjeras que no permitan el empleo del idioma del consumidor a tal fin. Como garantía adicional del derecho de acceso a tribunales, el defecto idiomático respecto de esta cuestión debería abrir la posibilidad de impugnar la validez el convenio arbitral de consumo.

\subsubsection{El tratamiento de los pactos arbitrales de consumo por el Derecho europeo: relaciones entre el régimen del art. 10 DRAL y el de las cláusulas abusivas}

El régimen que proporciona la DRAL a los pactos de remisión a entidades RAL no tiene por finalidad afectar a la aplicación de las normas europeas de protección del consumidor frente a cláusulas abusivas. Ambos regímenes son autónomos y, dependiendo de la compatibilidad concreta entre ellos, pueden ser complementarios, por lo que resulta del mayor interés averiguar el ámbito de aplicación de cada uno de ellos y el modo en que se determina la legislación estatal aplicable en cada caso.

En ocasiones el régimen del art. 10 DRAL y el de la abusividad de los pactos de arbitraje se solapa, quedando cubierto el segundo por el primero. Si el pacto de arbitraje de consumo no produce efecto cuando ha sido celebrado antes del surgimiento del litigio y no se ha hecho constar en un acuerdo separado, tal y como contempla el sistema alemán de cláusulas abusivas, de igual modo tampoco producirá ese efecto por el hecho de que no ha sido celebrado con posterioridad al surgimiento del litigio. La detección de este solapamiento invita a afirmar que el régimen del art. 10 DRAL ha sustituido al régimen de las cláusulas abusivas. En el sistema español, hasta 2014 el art. 57.4 del Texto Refundido de la Ley General para la Defensa de los Consumidores y Usuarios, consideraba como nulos a los pactos de arbitraje de consumo pactados con anterioridad al surgimiento del litigio que remitieran la solución del caso a entidades de arbitraje privadas no establecidas por la ley. En atención a la redacción actual de ese precepto, que proviene de la transposición del art. 10 DRAL, no resultan vinculantes para el consumidor los pactos de arbitraje de consumo celebrados con anterioridad al surgimiento del litigio, ya sea a entidades establecidas por ley o a entidades privadas. En atención a los problemas suscitados en el pasado, no habría sido descabellado que el legislador español hubiera mantenido la consideración como abusiva del pacto de arbitraje de consumo que remita a una entidad privada, a pesar de su carácter posterior al surgimiento del litigio. Ello no solo cuadra con las posibilidades de regulación de la DRAL, sino también con la circunstancia de que el propio legislador español contempla en el anteproyecto de ley de resolución alternativa de litigios de consumo la 
reserva a favor de entidades públicas, establecidas por la ley, del método de solución del arbitraje de consumo.

A favor del mantenimiento de la norma anterior se encuentra también el diferente alcance internacional de una y otra regulación en conformidad con las exigencias de los dos diferentes marcos de regulación europeos de procedencia. Respecto del propio de las cláusulas abusivas hay que estar a lo dispuesto por las normas nacionales de transposición del art. 6.2 de la Directiva 93/13/CE. En cuanto al segundo, con arreglo al criterio de interpretación que hemos propuesto, a la ubicación de la residencia del consumidor en un Estado miembro y el establecimiento del empresario en un Estado miembro. Los casos no cubiertos por el régimen del art. 10 DRAL deberían poder caer, en su caso, bajo la aplicación de los criterios de aplicabilidad establecidos para la Directiva 93/13/CE, algo que no será posible en el sistema español.

Por otra parte, la sustitución operada en el régimen español provoca otra consecuencia, a la vista de la incertidumbre razonable en torno a si la regulación procedente del art. 10 DRAL podrá ser apoyada con el acervo europeo sobre protección del consumidor frente a cláusulas abusivas ${ }^{55}$, algo a lo cual solo cabrá llegar como consecuencia de una operación interpretativa no exenta de dificultades. A la vista del ámbito de aplicación internacional diferente de uno y otro régimen, y mientras se descifra si al nuevo le han de resultar aplicables los procedimientos establecidos para el control judicial de las cláusulas abusivas, creemos que habría sido prudente conservar tal cual el régimen anteriormente en vigor.

\subsubsection{El nuevo valor del orden público en los pactos de sometimiento a tribunales arbitrales de consumo extranjeros}

La admisión que hace el Derecho europeo del arbitraje de consumo como método de solución de las entidades RAL tiene un efecto importante sobre el sistema general. Hasta ahora ha sido unánimemente aceptado que resulta en contradicción con el orden público la sumisión del consumidor a un arbitraje extranjero en cuanto ello supone la renuncia a las competencias propias de los contratos celebrados por los consumidores. Aquí aparece uno de los mayores impactos del nuevo Derecho europeo sobre el tratamiento de las reclamaciones transfronterizas, algo que ha pasado casi desapercibido a través de la mención que se ha hecho en el art. 2.4 DRAL a los procedimientos que finalizan con una decisión vinculante para el consumidor. Aunque es posible discutir si las garantías ofrecidas por la DRAL son suficientes, una vez que el legislador ha admitido al arbitraje como método de solución que puede ser utilizado por las entidades RAL acreditadas, en el actual marco normativo generado no tiene cabida la referida limitación del orden público. Ello no significa que no sea posible proponer garantías adicionales de cara a mejorar la posición del

55 SSTJ de 6 de octubre de 2009, asunto C-40/08, ECLI:EU:C:2009:615; y de 26 de octubre de 2006, asunto C-168/05, ECLI:EU:C:2006:675. 
consumidor en los procedimientos de arbitraje de consumo respecto de reclamaciones transfronterizas, tales como las que han sido indicadas.

\subsubsection{La necesaria transposición del principio de libertad en todos los Estados miembros}

La existencia del régimen particular existente respecto de la validez y el carácter vinculante del acuerdo de arbitraje de consumo como el descrito hará necesario adaptar, aunque sea de manera interpretativa, la regulación de la declinatoria por acuerdo de arbitraje. En el caso del sistema español la regulación relativa a los pactos de arbitraje ha de alterar el funcionamiento del art. 63 de la Ley de Enjuiciamiento Civil, debiendo ser especialmente objeto de control la existencia de un consentimiento informado. Será asimismo necesario que aquellos Estados que, como Alemania, van a prescindir de acreditar a entidades RAL de arbitraje de consumo, no obvien, como parecen estar haciéndolo, la necesidad de realizar también la transposición del art. 10 DRAL para disponer de esta herramienta especialmente para el caso de los supuestos transfronterizos.

Por poner un ejemplo gráfico, si un consumidor con residencia en Alemania realiza una compra en línea de un vendedor con establecimiento en España, con arreglo al sistema actualmente en vigor en Alemania el juez alemán podrá estimar la excepción de arbitraje, y dejará de conocer, como consecuencia de la existencia de un acuerdo que haya sido celebrado con anterioridad al surgimiento del litigio en la medida en que este pacto haya sido celebrado a través de un acuerdo separado. Se da así lugar a una solución diferente a la que contempla el nuevo Derecho europeo, bajo el cual no son vinculantes para el consumidor los pactos de arbitraje de consumo celebrados antes del surgimiento del litigio. Solo a través de una previsión en el sistema alemán, y en el del resto de los Estados miembros, será posible conseguir que se corrija esta disfunción para dar respuesta a los supuestos transfronterizos.

\subsubsection{Ley aplicable al procedimiento ante las entidades $R A L$}

A pesar de que el régimen general suele permitir que, en lo referido al procedimiento, las partes elijan la ley aplicable, en la práctica, la adhesión del consumidor al procedimiento ante una entidad RAL establecida en un Estado miembro determinará que sea de aplicación la ley de este país. La ley aplicable al procedimiento aparecerá así convertida en la ley del país de la acreditación de la entidad RAL. Cada Estado habrá de decidir el procedimiento que habrá de ser seguido por sus entidades RAL y, en su caso, establecer las variaciones respecto de lo dispuesto por la DRAL que sean permitidas por esta. La ley aplicable, por ejemplo, determinará el uso que el Estado hace del art. 5.4 DRAL, estableciendo la posibilidad del rechazo de la reclamación si antes no ha sido presentada al empresario, o si es posible rechazar reclamaciones extemporáneas o frívolas. 


\subsubsection{El respeto al Derecho imperativo aplicable al contrato de consumo}

Respecto del fondo del litigio, la introducción del principio de legalidad representa una de las garantías adicionales que la DRAL ha considerado importantes para admitir los métodos de solución que finalizan con una decisión vinculante para las partes, como ocurre también en el caso del arbitraje de consumo. El legislador europeo no ha tenido, sin embargo, excesiva fortuna a la hora de acuñar el principio, no teniendo en cuenta, por ejemplo, que el Reglamento Roma I ha incluido un nuevo apartado cuarto en el art. 3 con el propósito de garantizar la aplicación del Derecho europeo de protección de los consumidores cuando el contrato presenta todos los puntos de contacto con países miembros de la Unión Europea, o que hay Directivas, como la 1993/13/CE o la 1999/44/CE, que constituyen el fundamento para soluciones especiales de ley aplicable que existen en las legislaciones de los diferentes Estados miembros de la Unión Europea ${ }^{56}$. Para que el arbitraje de consumo pueda tener un acomodo en el sistema europeo de resolución alternativa de litigios de consumo más conforme con las garantías que derivan del derecho a la tutela judicial efectiva, creemos necesario que el principio de legalidad que se proclama aparezca protegido mediante un dispositivo que permita la posibilidad de que el laudo pueda ser impugnado por infracción de las normas imperativas de protección del consumidor, especialmente en los supuestos en los que la decisión de los árbitros es dictada en equidad, algo que es harto frecuente tal y como ocurre en el sistema español actual. De otro modo, en aras de la resolución ágil creemos que se cierra en falso la efectividad de los derechos reconocidos a los consumidores por el sistema europeo. Todo apunta a que será la ley del país de la sede de la entidad RAL la que deberá decidir sobre los motivos de impugnación del laudo. Por otra parte, a pesar de que dicha garantía no es establecida por la DRAL, la ley del país de la sede de la entidad RAL deberá decidir si cabe o no la impugnación del acuerdo de mediación alcanzado por su carácter lesivo o por suponer una renuncia, contraria al orden público de los derechos del consumidor.

\section{CONCLUSIONES}

El nuevo Derecho europeo sobre resolución alternativa y en línea de litigios de consumo representa una regulación inédita en Europa y pionera a nivel mundial a la hora de establecer un marco institucional decidido a favorecer la resolución en línea de litigios de consumo. Queda sin embargo por ver cuál será el éxito de la nueva regulación, pues por ahora no todos

56 Sobre la construcción compleja del sistema europeo de ley aplicable a los contratos de consumo electrónicos, véase ESTEBAN DE LA ROSA, F., «Régimen jurídico de la contratación electrónica internacional de consumo en el sistema español de Derecho internacional privado», Aranzadi Civil, vol. 2, 2009, pp. $15-45$. 
los Estados miembros cuentan con entidades acreditadas y el número de quejas que ha recibido la plataforma europea no es numeroso. A partir de ahora será preciso la colaboración de todos en la difusión y en la detección de errores y problemas, algunos de los cuales han sido apuntados por este estudio.

La estructura creada está llamada a producir un efecto multiplicador del número de las reclamaciones transfronterizas, lo que abre nuevos retos para la regulación del sistema de Derecho internacional privado desde dos perspectivas diversas. Por una parte, resulta necesario hacer una puesta a punto, y comprobar con qué sistema nos encontramos en la actualidad mediante la combinación de las soluciones especiales y las generales. Por otra, resulta necesario revisar si las soluciones actuales responden a las exigencias especiales que provienen del reconocimiento del derecho a la tutela judicial efectiva en conformidad con los arts. 47 CEDF y 19 TUE.

En la revisión efectuada hemos detectado insuficiencias en las soluciones de Derecho internacional privado existentes a fin de garantizar la aplicación del art. 10 DRAL en todo su ámbito de aplicación espacial, así como la conveniencia de seguir contando con un régimen especial para los pactos de arbitraje de consumo desde el ámbito de las cláusulas abusivas, habida cuenta de los términos de aplicabilidad diferentes de ambos regímenes en el plano internacional. Hemos indicado la necesidad de entender superada, para el funcionamiento de la plataforma europea, la interpretación según la cual resulta en contradicción con el orden público el sometimiento a un arbitraje de consumo extranjero. El nuevo régimen hace también aflorar algunas lagunas de regulación que han de ser integradas, como la relativa a la determinación del Derecho aplicable a la obligación de participar en procedimientos ante entidades.

En el plano de la conformidad del nuevo régimen con el derecho a la tutela judicial efectiva creemos que resulta necesario proporcionar un mejor acomodo en el sistema europeo a la institución del arbitraje de consumo, a través del establecimiento, en cada Estado miembro, de un dispositivo de impugnación del laudo por infracción de normas imperativas de protección del consumidor. Solo de este modo es posible dar respaldo y garantía a la proclamación que se hace del principio de legalidad. Por otra parte, hemos advertido la necesidad de contar con una regulación sobre el idioma del procedimiento que logre salvaguardar la efectividad de los principios de equidad y de libertad en los supuestos transfronterizos. Para garantizar la efectividad de los derechos reconocidos respecto de reclamaciones transfronterizas resulta necesario que cierta información mínima sea transmitida en el idioma del consumidor o, al menos, en el idioma en que la reclamación fue presentada. En ningún caso debería ser suficiente el empleo para este fin del idioma en el que fue realizada la transacción. Los elementos mejorables detectados no logran ocultar la trascendencia de la nueva regulación europea, que está llamada a ser un instrumento indispensable para la generación de confianza en el comercio electrónico del futuro. 


\section{RESUMEN}

\section{RÉGIMEN DE LAS RECLAMACIONES DE CONSUMO TRANSFRONTERIZAS EN EL NUEVO DERECHO EUROPEO DE RESOLUCIÓN ALTERNATIVA Y EN LÍNEA DE LITIGIOS DE CONSUMO}

El carácter global del comercio de consumo en línea ha hecho aparecer nuevas estrategias para la garantía de los derechos de los consumidores, como la consistente en permitir la propia resolución en línea de los litigios. El nuevo Derecho europeo, contenido en la Directiva 2013/11/UE y el Reglamento 524/2013/UE, ha supuesto la acogida a nivel regional de esta tendencia. Este estudio analiza el impacto de los nuevos textos europeos sobre el sistema de Derecho internacional privado. Por una parte, revela la necesidad de hacer ajustes en el referido sistema a fin de conseguir, entre otros objetivos, un ámbito de aplicación espacial para el principio de libertad acorde con la intención perseguida por el legislador europeo, de superar la interpretación que descarta la remisión a un arbitraje de consumo extranjero o de integrar las lagunas de regulación que ha hecho aflorar el nuevo sistema. Por otra, pone el foco en la necesidad de comprobar si el régimen actual resulta en conformidad con las exigencias que provienen de los derechos proclamados por el art. 47 CEDF y el art. 19 TUE. En esta perspectiva se proponen soluciones de lege ferenda asociadas a las necesidades especiales de la gestión en línea de reclamaciones transfronterizas a través de la plataforma europea.

Palabras clave: Derecho europeo, resolución en línea de litigios, protección del consumidor, Derecho internacional privado.

\section{ABSTRACT \\ CONSUMER COMPLAINTS' REGIME IN THE NEW EUROPEAN LAW ON ALTERNATIVE AND ONLINE CONSUMER DISPUTE RESOLUTION}

The global nature of online consumer trade has given rise to new strategies guaranteeing consumer rights, such as enabling online dispute resolution. The new European law, namely Directive 2013/11/EU and Regulation 524/2013/EU, has boosted regional acceptance of this trend. The present study analyses the impact of the new European legislation on the system of private international law. The study reveals, on the one hand, the need to make systematic adjustments in order to achieve a spatial scope of application for the principle of liberty according with the EU legislator's intention, to avoid the interpretation excluding the reference to foreign consumer arbitration or to integrate some regulatory gaps inherent to the newly established system. On the other hand, it focuses on the need to verify whether the current regime complies with the requirements derived from the recognition of the right proclaimed by art. 47 ECFR and art. 19 TEU. In this perspective the study contains de lege ferenda solutions intertwined with the peculiarities of the online management of cross-border claims via the European platform.

Keywords: European Law, online dispute resolution, alternative dispute resolution, consumer protection, international private law. 